\title{
ERRATUM
}

\section{Erratum to: Analysis of the mechanical property of mudstone/shale in paralic coal measures and its influence factors}

Zhao-ping MENG, Xian-ming XIAO

(c) The Editorial Office of Journal of Coal Science and Engineering (China) and Springer-Verlag Berlin Heidelberg 2013

Erratum to: JOURNAL OF COAL SCIENCE \& ENGINEERING (CHINA)

DOI 10.1007/s12404-013-0101-z

The original version of this article unfortunately contained a mistake. The second author "Xian-ming XIAN" is incorrect. It should be "Xian-ming XIAO".

The online version of the original article can be found at http://dx.doi.org/10.1007/s12404-013-0101-z

Zhao-ping $\mathrm{MENG}^{1}$, Xian-ming XIAO ${ }^{2}$

1. College of Geosciences and Surveying Engineering, China University of Mining \& Technology (Beijing), Beijing 100083 , China

2. Guangzhou Institute of Geochemistry, Chinese Academy of Sciences, Guangzhou 510640, China 